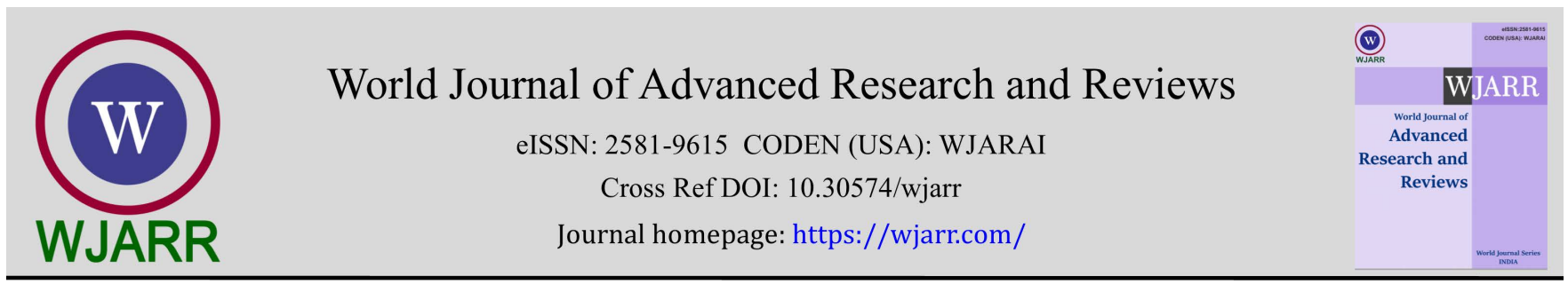

(REVIEW ARTICLE)

\title{
Mortality of covid19 in sickle cell disease systematic review
}

\author{
Waseem Bader AlTalalwah ${ }^{1, *}$ and Shorok Ali AlDorazi ${ }^{2}$ \\ ${ }^{1}$ King Abdullah International Medical Research Center/King Saud bin Abdulaziz University for Health Sciences, College of \\ Medicine, Department of Basic Medical Sciences, Hospital - NGHA, Riyadh 11481, Saudi Arabia. \\ 2 Ministry of Health, Eastern province, Dammam, infection control.
}

World Journal of Advanced Research and Reviews, 2021, 12(02), 151-156

Publication history: Received on 20 September 2021; revised on 01 November 2021; accepted on 03 November 2021

Article DOI: https://doi.org/10.30574/wjarr.2021.12.2.0526

\begin{abstract}
The covid19 infection is pandemic disease are more commonly in chronic diseases. As covid19 case pulmonary infection, the current study focuses on sickle cell disease patients are suitable to acute chest syndrome. It will clarify the risk factors for covid19 infection and its clinical features in sickle cell disease. It also reviews the radiological findings to gain more data on this pandemic disease. The current study includes 44 cases of sickle cell disease having covid19 infection. The entire cases include sickle cell disease only in $89 \%$ whereas the other sickle cell disease cases are coexisted with beta- thalassemia in $9.1 \%$. The fourth decade is the highest peak incidence. There are several complications found to be in sickle cell disease are acute chest syndrome, chronic leg ulcer, renal failure exceeding $10 \%$. The bronchial asthma found to be in $6.9 \%$ and avascular necrosis found to be $11.4 \%$ whereas the cerebrovascular accident found to be in $13.8 \%$. The radiological changes include lung tissues, alveoli, pleural cavities and pulmonary arteries in different rate. The incidence of recovery found to be in $93 \%$ whereas the death found to be in $7 \%$. It found to be involving in respiratory and gastrointestinal systems result in different clinical features in different rate. This study compares the clinical features, findings investigation and complications between sex and decades. Further, this study clarifies recovery and mortality rate between sex and decades. Knowing and understanding covid19 infection in sickle cell disease, physicians will be able to provide high quality of medical services.
\end{abstract}

Keywords: Covid19; Pandemic; Pulmonary; Sickle Cell Disease; Acute Chest Syndrome; Avascular Necrosis

\section{Introduction}

As the covid19 is a pandemic disease, patients with sickle cell disease and treating physician raise several Concerns regarding the susceptible of covid19 infection as a risk factor in which the sickle cell patient is more likely to susceptible to acute chest syndrome [1-3]. Beside infection, the aggravating factors of sickle cell crisis are hypoxia, acidosis and dehydration which are also consequences of infection [1]. The acute chest syndrome is a major reason of death therefore the current study will focus on finding to identify the risk factors rate and correlate with mortality. The current study involves the duration of diagnosis based on clarification of clinical features and investigations. It measures the gender and age to provide more information of risk factors in relation to covid19 infection. The current study will describe the recovery and death incidence and duration by reviewing the entire cases considering the existence of the risk factors.

\section{Material and methods}

Current study investigates patients with sickle cell disease who have covid19 infection. It measures the risk factors of covid19 infection and its clinical features. Also, it reviews the chest- X-ray and computed tomography (CT) to measure

\footnotetext{
${ }^{*}$ Corresponding author: Waseem Al Talalwah

King Abdullah International Medical Research Center/King Saud bin Abdulaziz University for Health Sciences, College of Medicine, Department of Basic Medical Sciences, Hospital - NGHA, Riyadh 11481, Saudi Arabia.
}

Copyright (C) 2021 Author(s) retain the copyright of this article. This article is published under the terms of the Creative Commons Attribution Liscense 4.0. 
the changes such as pulmonary embolism or other organ involves in coexistence of covid19 infection. Further, the follow up investigation will provide many findings indicating either the effectiveness or ineffectiveness of treatments. It also determines the incidence of recovery and critical fatality rate in patients with sickle cell disease. The literatures linked to sickle cell disease and covid19 are attained from PubMed and Google Scholar database. The entire articles have been published in 2020 found to be almost hundreds articles. The entire articles are founded and selected based on the keyword 'sickle cell, corona virus and covid19. The articles are selected only in English language. Out of hundreds articles, 44 cases found to be relevance to the study were collected from January to August 2020. The data is collected and analysis via Statistical Package for the Social Sciences (SPSS).

\section{Results}

The main complain of sickle cell patients attending to emergency department is pain due to vasoocclusive crises estimated in $95 \%$ in current study. The remain is due to gastrointestinal symptoms such as nausea, vomiting and diarrhoea in $2.3 \%$ as well as due to delivery of pregnancy. The entire cases include sickle cell disease only in $89 \%$ whereas the other sickle cell disease cases are coexisted with beta- thalassemia in 9.1\%. The incidence of male and female is $44.4 \%$ and $55.6 \%$ respectively. Based on decade, the incidence of covid 19 found to be in $18.2 \%$ of first decade, $13.6 \%$ of second, 13.6 of third, $40.9 \%$ of fourth, $9.1 \%$ of fifth and $4.5 \%$ of sixth (Figure 1 ). The diagnosis is based on nasopharyngeal swab taking in first day in $47.7 \%$, second day in $6.8 \%$, third day in 31.8 , seventh day in $4.6 \%$, eleventh day in $4.6 \%$ whereas the nasopharyngeal swab has done twice in $4.5 \%$ in the third day. Based on medical history, the sickle cell disease patients have several conditions such as acute chest syndrome in $2.3 \%$, Splenectomy in $2.3 \%$, iron overload in $2.3 \%$, chronic leg ulcer in $2.3 \%$, renal failure on haemodialysis in $2.3 \%$ whereas pregnancy found to be in $2.3 \%$. Further, the sickle cell patient having bronchial asthma found to be in $6.9 \%$ whereas avascular necrosis of the femur and humour found to be $9.1 \%$ and $2.3 \%$ respectively. Moreover, the sickle cell patients having cerebrovascular accident found to be in $13.8 \%$. In few cases of sickle cell disease, the glucose 6 phosphate dehydrogenase deficiency (G6PD) found to be in $18.2 \%$. According to radiological studies such as chest- $\mathrm{x}$-ray and computed tomography, the opacity found to be in $37.2 \%$ indicating involvement of lung tissues whereas the other findings such as atelectasis indicating partial collapse of lung alveoli in 2.3\%, cardiac effusions in $4.6 \%$ and pulmonary embolism in $4.6 \%$. The haemoglobin level ranges from 6 to $11.5 \%$ and haemolysis found to be in $39.3 \%$ (Figure 2). Beside the pain crisis, the main clinical features involve fever in 34.9\%, cough 41.9\%, shortness of breath (chest tightness) or nonspecific chest pain in $39.5 \%$, nasal congestion in $11.6 \%$ which are classified under respiratory symptoms in $67.5 \%$ which differ in their presentation from one patient to other whereas gastrointestinal system which are nausea, vomiting and diarrhoea in $2.3 \%$ (Figure 3 ).

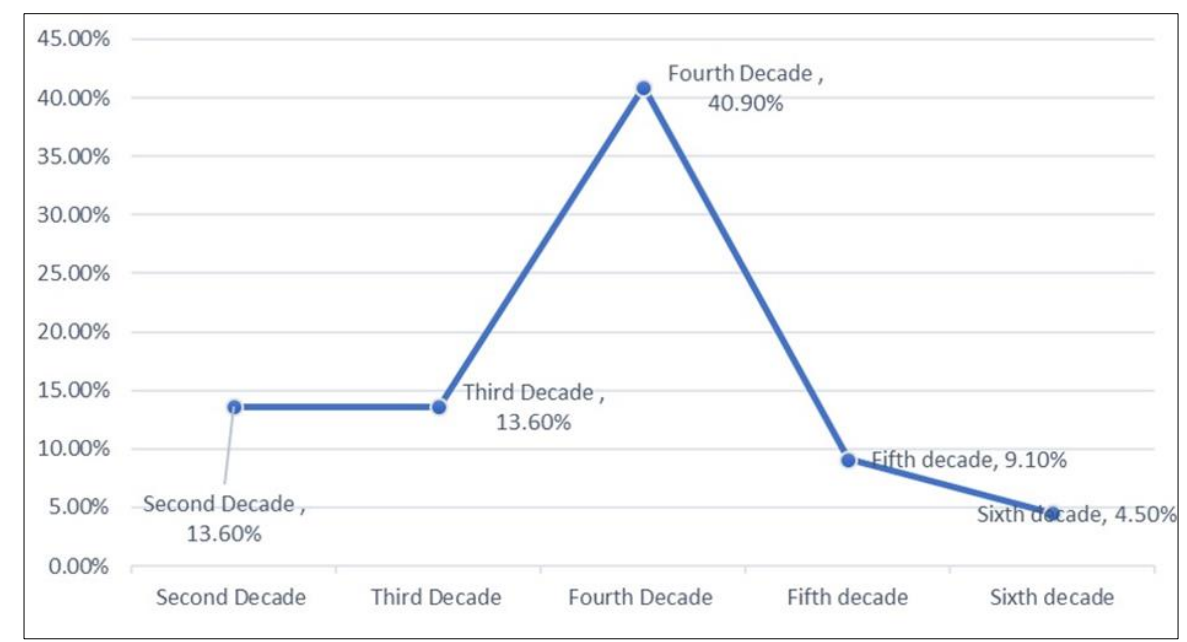

Figure 1 The incidence of covid19 in sickle cell patient's decades

Based on laboratory, the leucocytosis found to be high in $6.9 \%$ and lymphocytopenia in $27 \%$. The pulse oximetry shows desaturation in $45.4 \%$ however they need oxygen support in $61.4 \%$ including non-invasive $56.8 \%$ and invasive in $4.6 \%$. The patients receive anticoagulant therapy in 54.5\%. Different medications have been used in treatment are azithromycin $31.8 \%$, cefotaxime in $27.3 \%$, hydroxychloroquine in $11.5 \%$, hydroxyurea in $9.2 \%$, tocilizumab in $4.6 \%$, ceftriaxone in $2.3 \%$, deferoxamine in $2.3 \%$ and zosyn in $2.3 \%$. The incidence of recovery found to be in $93 \%$ whereas the death found to be in $7 \%$. The incidence of recovery from hospital management is $72.3 \%$ whereas $20.7 \%$ is from home management. 


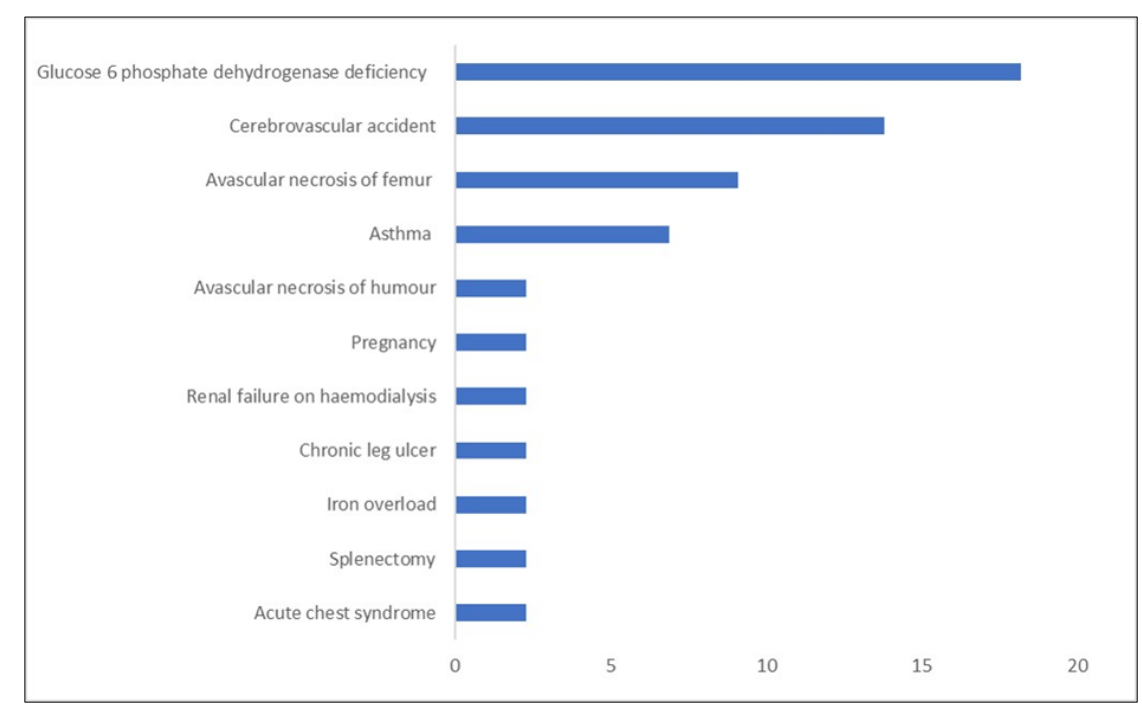

Figure 2 The incidence of covid19 in sickle cell patients with coexistence of risk factor conditions

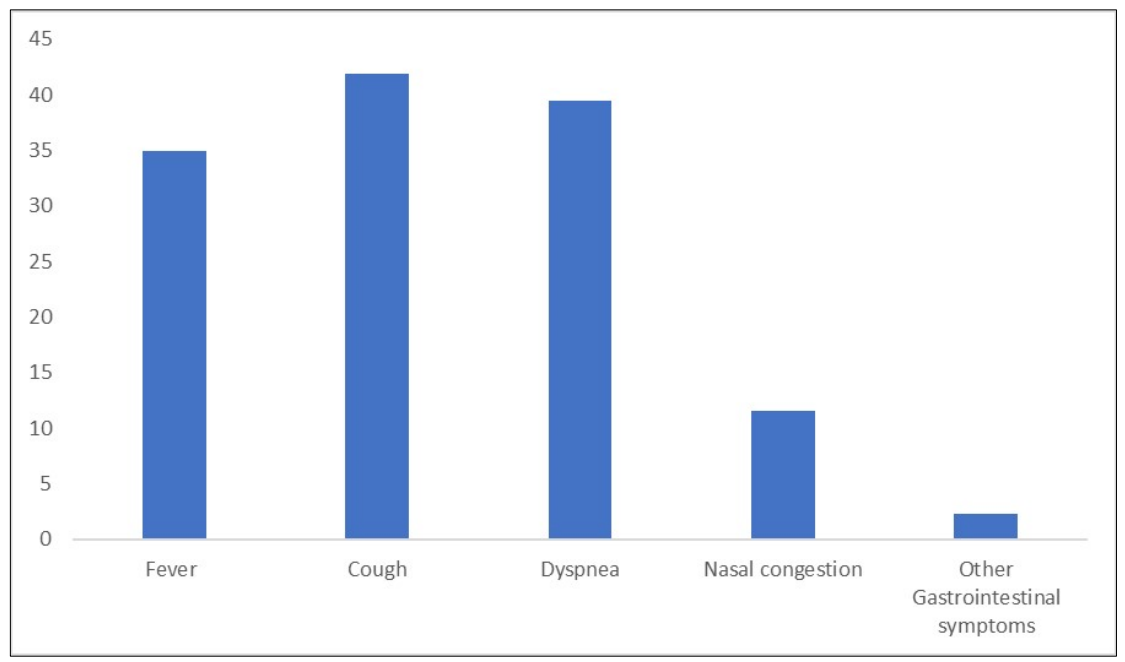

Figure 3 The incidence of covid19 symptoms in sickle cell patients

Based on decade, the incidence of death is $5.5 \%$ in fourth decade, $16.6 \%$ in second and $50 \%$ in sixth. On the other hand, the incidence recovery is $100 \%$ in first, third and fifth whereas the recovery is $94.5 \%$ in fourth decade, $83.4 \%$ in second and $50 \%$ in sixth. Based on clinical feature, the incidence of fever is $50 \%$ of fifth and $50 \%$ of sixth, $66.6 \%$ of third, $72.2 \%$ of fourth, $100 \%$ of second whereas the first decade has not recorded any fever. Based on clinical feature, the incidence of cough is $25 \%$ of fifth, $38.8 \%$ of fourth $83.3 \%$ of sixth. $50 \%$ of third whereas the first decade has not recorded any cough. Based on clinical feature, the incidence of shortness of breath or nonspecific chest pain is $50 \%$ of fifth and sixth, $33.3 \%$ of fourth, $66.6 .3 \%$ of second and third whereas the first decade has not recorded any chest tightness. Based on radiological findings, the incidence of opacity is $25 \%$ of fifth, $33.3 \%$ of fourth, $50 \%$ of third and $100 \%$ of second whereas the first and sixth decade has not recorded any findings. Acute chest syndrome is risk factor found to be mainly in fourth decade in $5.5 \%$ as well as chronic leg ulcer is risk factor found to be mainly in fourth decade in $5.5 \%$. Chronic renal disease on haemodialysis is risk factor found to be mainly in fourth and fifth decade in $5.5 \%$ and $25 \%$. The iron overload is risk factor found to be mainly in $25 \%$ of fifth decade. G6PD is risk factor found to be mainly in $100 \%$ of first decade. Avascular necrosis of femur is risk factor found to be mainly in 5.5\% of fourth, 33.3\% third and 50\% of sixth decade. Avascular necrosis of humerus is risk factor found to be mainly in $50 \%$ of sixth decade. Cerebrovascular accident is risk factor found to be in $25 \%$ of fifth, $22.2 \%$ of fourth and $16.6 \%$ of third decade.

Based on sex comparison, the incidence of death in male is $8.3 \%$ and female $6.6 \%$ whereas the incidence of recovery is $91.7 \%$ in male and $93.4 \%$ in female. Acute chest syndrome is risk factor found to be in $6.6 \%$. Female. Chronic leg ulcer is risk factor found to in female $6.6 \%$. Chronic renal disease on haemodialysis is risk factor found to be in male is $8.3 \%$ and female $6.6 \%$. The iron overload is risk factor found to be in female $6.6 \%$. Avascular necrosis of femur is risk factor 
found to be in male is $16.6 \%$ and female $13.2 \%$. Avascular necrosis of humerus is risk factor found to be in female $6.6 \%$. Cerebrovascular accident is risk factor found to be in in $16.6 \%$ male and $19.8 \%$ female Asthma risk factor found to be in $19.8 \%$ female. The radiologic findings such as opacity found to be in male is $85.1 \%$ and female $26.4 \%$ whereas atelectasis found to be in $8.3 \%$ male and $13.2 \%$ pulmonary embolism and $13.2 \%$ cardiac effusion in female. The haemoglobin level is below $10 \mathrm{~g} \backslash \mathrm{dl}$ found to be in $66.6 \%$ male and $39.6 \%$ female. Haemolysis found to be in $33.3 \%$ male and $26.4 \%$ female.

\section{Discussion}

Sickle cell disease is most common hemoglobin disorders of the world's population with incidence rate of 5\%. The incidence of sickle cell disease is more than 75\% in sub-Saharan Africa (WORLD HEALTH ORGANIZATION) [4]. The gene of entire cases sickle cell disease classified into HgbSS or HgbSC in 89\%.1 whereas HgbSB (beta- thalassemia) in $9.1 \%$. The chief complain of sickle cell patients is pain because of vasoocclusive crises estimated in $95 \%$ in current study. The incidence covid19 in entire sickle cell disease found to be more in female (55.6\%) than male (44.4\%). Further, the highest incidence of covid19 found to be fourth decade (40.9\%) comparing to other six decades (figure 1). In fact, the infection, hypoxia, dehydration, or acidosis inked to clinical and laboratory presentation are aggravating factors to vasoocclusive crisis [1]. Since the respiratory infection is aggravating factors to acute chest syndrome [1], the acute chest syndrome mimics clinical features and investigations of covid19 respiratory infection from mild to severe conditions [5-16]. In current study, the sickle cell anemia present with vascooclusiove pain due to covid19 infection which has been approved by nasopharyngeal swap in all cases of different days of admission with a majority of first and third days due to clinical features presentation.

The risk factors associated with sickle cell disease are acute chest syndrome, Splenectomy, iron overload, chronic leg ulcer, renal failure on hemodialysis found to be equal in $2.3 \%$ which may decrease immunity and high predispose to infection. Further, bronchial asthma may increase the mortality rate of respiratory infections in sickle cell disease found to be in $6.9 \%$. the avascular necrosis of the femur and humour found to be $11.4 \%$ indicating insufficient blood supply of bone and its bone marrow by series of vaso-cclusions. Hydroxycarbamide (hydroxyurea) is another risk factor for suitable infection in sickle cell disease [1] found to be in $9.2 \%$ in current study. Also, the cerebrovascular accident indicates risk of thrombosis found to be $13.8 \%$. As the thrombosis is risk factor in sickle cell disease, the anticoagulant therapy provided in $54.5 \%$ of all cases. On the other hand, hemolysis can increase the risk of sickle cell disease crisis in coexisting of the glucose 6 phosphate dehydrogenase deficiency (G6PD) with incidence of $18.2 \%$. The chest X-ray is mandatory in Sickle cell patient presenting with respiratory features. The radiologic result of infiltration presenting as opacity in COVID-19 positive patients or Sickler patients indicating acute chest syndrome [5-16]. According to current study of radiological investigation, the infiltration of different lung lobe found to be in $37.2 \%$ indicate involvement of lung tissues however associated complication of covid 19 pulmonary infection such as cardiac effusions in $4.6 \%$ and pulmonary embolism in $4.6 \%$. According to laboratory, hemolysis found to be in $39.3 \%$. of entire cases indication covid19 infection is high risk factors of hemolysis in sickle cell anemia (Figure 2). Further, $27 \%$ of sickle cell entire cases have lymphocytopenia indicate that covid19 decreases immunity in sickle cell disease. Hypoxia is due to covid19 and aggravating factors of sickle cell crisis found to be in $45.4 \%$. The sickle cell patients receive oxygen support in $61.4 \%$ including non-invasive $56.8 \%$ and invasive in $4.6 \%$ due desaturation in $45.4 \%$ via pulse oximetry to eliminate hypoxia as an aggravating factor due to covid19 infection.

In fact, the clinical pictures are linked to involving organs as the COVID19 penetrates cell membrane by binding to angiotensin-converting enzyme 2 (ACE2) and causes pulmonary infection or other organs such as brain, kidney, vascular smooth muscle, and skeletal muscles $[17,18]$. The clinical presentation of covid19 are mainly fever dry cough, and dyspnea [19]. found to be record the majority which is almost two third of entire cases whereas the gastrointestinal symptoms record the minority. The cough, dyspnea and fever are the common feature of covid19 infection in sickle cell crisis with incidence rate of $41.9 \%, 39.5 \%, 34.9 \%$ respectively (Figure 3). The nasopharyngeal swap has different days after admission based on respiratory symptoms. Accordingly, emergency physicians need to be alert for possibility of delay of respiratory symptoms since the infection of covid19 can be the reason behind of vaso-occlusive crisis.

The fatality ratio increase as the age increases [20] therefore current study measures the risk factors, clinical presentations and mortality considering decade and sex. In covid19 Sickler, most of the death and recovery is equal in sixth decade (50\%) whereas the death less than $17 \%$ and recovery rate is higher than $83 \%$ in previous decades. Based on clinical feature, fever is $50 \%$ in fifth and sixth and more than $50 \%$ in second, third and fourth. On the other hand, the fever is absent in the first decade. The cough is majority in sixth decades and less than $50 \%$ in third, fourth and fifth however cough is absent in first decade too. The incidence of shortness of breath is $50 \%$ and below in fourth and fifth whereas it is above in second and third however shortness of breath is absent in first decade. Therefore, a great attention for treating physician for first decade since patient is asymptomatic covid19 in sickle cell disease. Based on radiological 
findings, the infiltration of lung tissue is 50\% and below in fourth and fifth and completely in second however the infiltration is absent in first and sixth decades. This great alert for physician to be careful in diagnosis and decision of treatment as inpatient or outpatient for the first decades. Moreover, the fourth decade include majority of risk factors such as Acute chest syndrome chronic leg ulcer, Chronic renal disease, Cerebrovascular accident and Avascular necrosis of femur which increases as incidence age based on lifestyle may present with variable incidence. The risk factors are linked with thrombosis which is due to sickle cell disease producing coagulopathy therefore the physicians should have great attentive in treating immunocompromised covid19 patients who usually on hydroxyurea leading to decrease immunity too. Based on sex comparison, the atelectasis, avascular necrosis of femur and chronic renal disease on haemodialysis is risk factor found be more in male on the other hand cerebrovascular accident is risk factor found to be more in female. The other risk factors are acute chest syndrome, chronic leg ulcer, pulmonary embolism, iron overload, asthma and avascular necrosis of humerus found to be only in female. The radiologic findings found to be more in male than female. However, the pulmonary embolism and cardiac effusion found to be in female. The male is lower than female in haemoglobin level below $10 \mathrm{~g} \backslash \mathrm{dl}$ which is due to haemolysis found to be more in male than female.

The incidence of recovery in covid19 in sickle cell disease found to be in $93 \%$ which is more in female than in male. On the other hand, the incidence death in covid19 in sickle cell disease found to be in $7 \%$ of entire cases which is more male than female. The incidence of death is on sixth decades due to risk factors comparing to other decades. Since the most patent with sickle cell disease has increase rate of Intensive care unit admission, the incidence of recover and death in patient with sickle cell disease is close international rate (world meter).

\section{Conclusion}

The first decade patients with sickle cell disease are asymptomatic patients of covid19 being high risk of spread of infections therefore great precaution must be done in clinical and laboratory from health workers such physicians, nurse and technicians through laboratorial, radiology and surgical procedures during examination, investigation and management using isolation room and personnel protecting equipment in emergency room and admission. The patient with sickle cell disease is at high risk of intensive care unit and may present with clinical features of vasooclusive crisis behind serious covid19 infection. Emergency physician should admit him under observation for twenty-four hours to control pain and rule out of covid19. Infection control division should be providing protocol in admission procedure for health administrative management with clear plan to avoid spread of infection between patients and health workers as well as minimizing the spread in society.

\section{Compliance with ethical standards}

\section{Acknowledgments}

I would take opportunity to acknowledge people who stress me to produce positive side and to expand my research vision as long as increase their efforts to make the challenge more difficult in my profession. Also, I would like to thank Professor Roger Soames who support me by encouraging and inspiring instead of despairing me or providing obstacles. Finally, I would like to thank my mum (Mariam Abdulhay Al Abdalnabi) passed away on Friday (23-7-2021) due to outbreak infection in hospital and entire medical employees who served her well.

\section{Disclosure of conflict of interest}

There is no conflict of interest.

\section{References}

[1] Beerkens F, John M, Puliafito B, Corbett Virginia, Edwards C, Tremblay Douglas. COVID-19 pneumonia as a cause of acute chest syndrome in an adult sickle cell patient. Am J Hematol. 2020; 95(7):E154-E156.

[2] De Luna G, Habibi A, Deux JF, Colard M, Pham Hung d'Alexandry d'Orengiani AL, Schlemmer F, Joher N, Kassasseya C, Pawlotsky JM, Ourghanlian C, Michel M, Mekontso-Dessap A, Bartolucci P. Rapid and severe Covid19 pneumonia with severe acute chest syndrome in a sickle cell patient successfully treated with tocilizumab. Am J Hematol. 2020;95(7):876-878.

[3] Nur E, Gaartman AE, van Tuijn CFJ, Tang MW, Biemond BJ. Vaso-occlusive crisis and acute chest syndrome in sickle cell disease due to 2019 novel coronavirus disease (COVID-19). Am J Hematol. 2020; 95: 725-6. 
[4] WORLD HEALTH ORGANIZATION, FIFTY-NINTH WORLD HEALTH ASSEMBLY A59/9, Provisional agenda item 11.424 April 2006. Document EB116/2005/REC/1, summary record of the first and second meetings. Assembly/AU/Dec.81 (V). See document EB117/2006/REC/2, summary record of the fifth meeting.

[5] Hussain F, Njoku FU. Saraf SL, Molokie RE, Gordeuk VR, Han Jin. COVID-19 infection in patients with sickle cell disease. British Journal of Haematology, 2020; 189: 848-852.

[6] Atul M Desai, Chirag Desai, Hemshree Desai, Rutvij Desai. POSSIBLE ROLE OF T-AYU-HM PREMIUM AND OTHER HERBAL DRUG TREATMENTS IN COVID19. IJSDR 2020; 5(4): 272-274.

[7] Chowdhury S, Anwar S. Management of Hemoglobin Disorders during the COVID-19 Pandemic. Pandemic. Front. Med. 2020; 9(7):306.

[8] Corrons J, Sanctis V. Rare anaemias, sickle-cell disease and COVID-19. Acta Biomed. 2020; 91(2): 216-217.

[9] Gampel Bradley, Lucas A, Broglie L, Gartrell-Corrado R, Lee M, Levine J, Orjuela-Grimm M, Satwani P, Bender J, Roberts S. COVID-19 in New York City pediatric hematology and oncology patients. Pediatric Blood \& Cancer. 2000; 67(9):e28420.

[10] Heilbronner C, Berteloot L, Tremolieres P, Dupic L, Blanquat L, Lesage F, Odievre M. Patients with sickle cell disease and suspected COVID-19 in a paediatric intensive care unit. BJH. 2020; 190(1):e21-e24

[11] Liu W, Zhang S, Nekhai S, Liu S. Depriving Iron Supply to the Virus Represents a Promising Adjuvant Therapeutic Against Viral Survival. Current Clinical Microbiology Reports. 2020; 20:1-7.

[12] McCloskey KA. Meenan J, Hall R, Tsitsikas DA. COVID-19 infection and sickle cell disease: a UK centre Experience. BJH. 2020; 190(2):e57-e58.

[13] Patel N, Farooqi A, Callaghan M, Sethuraman U. Urinary Tract Infection in Febrile Children with Sickle Cell Disease Who Present to the Emergency Room with Fever. J. Clin. Med. 2020; 9: 1531.

[14] Roy N, Telfer P, Eleftheriou P,Fuente J, Emma Drasar, Shah F, Roberts D, Atoyebi W, Trompeter S, Layton DM, Lugthart S, Stuart-Smith S, Chakravorty S, Wright J, Porter J, Inusa B, Howard J. Protecting vulnerable patients with inherited anaemias from unnecessary death during the COVID-19 pandemic. BJH. 2020; 189: 635-639.

[15] Subarna Chakravorty, Giselle Padmore-Payne, Fester Ike, Virginia Tshibangu, Charlotte Graham, David Rees, and Sara Stuart-Smith. COVID-19 in patients with sickle cell disease - a case series from a UK Tertiary Hospital. Haematologica. 2020; 105.

[16] Sahu K, Siddiqui D, Cerny J. Managing sickle cell patients with COVID-19 infection: the need to pool our collective experience. BJH. 2020; 190(2):e86-e8.

[17] Cure E, Cumhur Cure M. Comment on “Organ-protective Effect of Angiotensin-converting Enzyme 2 and its Effect on the Prognosis of COVID-19”. J Med Virol. 2020; 92(9):1423-24.

[18] Echeverría-Rodríguez 0, Gallardo-Ortíz IA, Del Valle-Mondragón L, Villalobos- Molina R. Angiotensin- (1-7) participates in enhanced skeletal muscle insulin sensitivity after a bout of exercise. J Endocr Soc. 2020; 4(2):bvaa 007.

[19] da Rosa Mesquita R, Francelino Silva Junior LC, Santos Santana FM, Farias de Oliveira T, Campos Alcântara R, Monteiro Arnozo G, Rodrigues da Silva Filho E, Galdino Dos Santos AG, Oliveira da Cunha EJ, Salgueiro de Aquino $\mathrm{SH}$, Freire de Souza CD. Clinical manifestations of COVID-19 in the general population: systematic review. Wien Klin Wochenschr 2020; 133(7-8):377-382.

[20] Julien Riou, Anthony Hauser, Michel J. Counotte, Christian L. Althaus. Adjusted age-specific case fatality ratio during the COVID-19 epidemic in Hubei, China, medRxiv. 2020; 17(7): e1003189. 